\title{
A study on the effects of the fractal characteristics of aggregates on the mechanical behavior of cemented sand and gravel
}

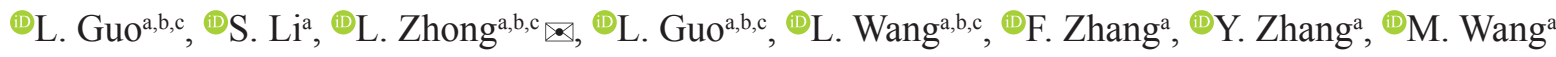 \\ a. School of Water Conservancy, North China University of Water Resources and Electric Power, (Zhengzhou, China) \\ b. Henan Water Valley Research Institute, (Zhengzhou, China) \\ c. Henan Key Laboratory of Water Environment Simulation and Treatment, (Zhengzhou, China) \\ 『250514782@qq.com
}

\begin{abstract}
Owing to complex aspects of cemented sand and gravel (CSG), such as included unscreened aggregates, CSG properties differ from those of ordinary concrete. Fractal theory is introduced to study the effects of aggregate characteristics on CSG properties, quantifying aggregate gradation and shape. Numerical simulation and analyses show that: (1) improved aggregate gradation decreases the gradation fractal dimension and increases the CSG peak stress and elastic modulus; (2) more irregularly shaped aggregates increase the shape fractal dimension and decrease the CSG peak stress and elastic modulus; (3) the relationship quantified between aggregate characteristics and CSG mechanical properties provides a theoretical basis for aggregate allocation in engineering design and construction. Mixing artificial aggregates can improve aggregate gradation but reduces CSG performance. Appropriately blending artificial and on-site aggregates achieves optimal CSG performance; in this study, this is attained using $20 \%$ artificial aggregates added under standard gradation.
\end{abstract}

KEYWORDS: Aggregate; Concrete; Mixture proportion; Modulus of elasticity; Mechanical properties.

Citation/Citar como: Guo, L.; Li; S.; Zhong; L.; Guo; L.; Wang, L.; Zhang; F.; Zhang, Y.; Wang, M. (2021) A study on the effects of the fractal characteristics of aggregates on the mechanical behavior of cemented sand and gravel. Mater. Construcc. 71 [342], e250. https://doi.org/10.3989/mc.2021.13020.

RESUMEN: Estudio del efecto de las características fractales de los áridos sobre el comportamiento mecánico de arena y grava cementada. La presencia de áridos no cribados en arena y grava cementadas (CSG) hacen que sus propiedades difieran de las del hormigón convencional. Se introduce la teoría fractal para estudiar los efectos de las características de los áridos en las propiedades de CSG, cuantificando la gradación y la forma de los áridos. La simulación numérica y el análisis muestran que: (1) la gradación mejorada de los áridos disminuye la dimensión fractal de la gradación y aumenta la tensión máxima y el módulo elástico de CSG; (2) áridos de formas más irregulares aumentan la dimensión fractal de la forma y disminuyen la tensión máxima y el módulo elástico de CSG; (3) la relación cuantificada entre las características de los áridos y las propiedades mecánicas de CSG proporcionan una base teórica para la asignación de los áridos en el diseño de ingeniería y en la construcción. La mezcla de los áridos artificiales puede mejorar la gradación de los áridos, pero reduce el rendimiento de CSG. Combinaciones adecuadas de áridos artificiales y naturales logran un rendimiento óptimo de CSG; en este estudio, esto se logra añadiendo un $20 \%$ de áridos artificiales con gradación estándar.

PALABRAS CLAVE: Áridos; Hormigón; Proporciones de mezcla; Módulo de elasticidad; Propiedades mecánicas. 


\section{INTRODUCTION}

Cemented sand and gravel (CSG) is a cementitious material of a known strength formed by mixing, paving, vibrating, and rolling a small amount of cementing material together with unscreened and unwashed gravels at the project site (1). Responding to the United Nations' call for new, green building materials (2), CSG can be used in modern dam construction technology to pursue efficient, low-cost construction while protecting natural resources. This has become the development trend toward future dam construction technology. CSG dam technology has been applied worldwide; permanent CSG dams have been built in Japan, Turkey, Greece, France, and elsewhere. It has also been gradually extended and applied in temporary works and in parts of permanent works in China. CSG dams are usually applied in areas where riverbeds provide abundant sand gravels. In order to broaden its applicability to more dam types, artificial aggregates can be used to replace natural aggregates for projects in riverbeds lacking natural gravels. Compared with natural aggregates, artificial aggregates have much larger surface areas owing to their multiple corner angles and rough surfaces. The presence of unscreened aggregates in CSG complexifies its aggregate characteristics; moreover, CSG properties are different from those of ordinary concrete. Aggregate type, shape, and grading are all important factors influencing the mechanical behavior of concrete materials $(3,4)$. Therefore, in order to provide a theoretical basis for CSG use in engineering design, it is necessary to systematically study the relationship between aggregate characteristics and CSG properties.

In recent years, an increasing number of studies have focused on the relationship between aggregate shapes and the resulting macroscopic properties of composite materials. Huang (5) proposed from his experiments that the more sphere-like the shape of a coarse aggregate, the greater the compressive strength and elastic modulus of the resulting concrete. Guo (6) found through experiments that, with increasing fractions of irregular particles, the slump and concrete strength of C30 and C50 concrete decrease. In research performed by Sánchez-Roldán et al. (7), it was observed that recycled coarse aggregates (RCA) have less angular shapes compared to natural aggregates; this characteristic, together with better particle coupling, provides greater compactness to the whole mixture. In addition to the shapes of aggregates, the shapes of other components in concrete have also been investigated. Research conducted by Zhang et al. (8) showed that the improved geometry of ultra-high-molecular-weight polyethylene (UHMWPE) fibers can ensure their uniform distribution in a matrix, significantly enhancing the splitting tensile strength and residual compressive strength of the resulting concrete.

In terms of numerical simulation, Xiong and Xiao (9) determined that round aggregates reduce the stress concentration intensity inside concrete compared to irregular aggregates; this suggests that the resulting concrete strength is relatively high, which is consistent with experimental results. On the basis of numerical simulation, Wang (10) proposed that the average peak stress of the tensile strength of round aggregates is slightly higher than that of polygonal aggregates for the same volume fraction of aggregates and pores. Numerical modeling by Zheng et al. (11) implied that changes in aggregate shape cause stress concentrations that affect the strength of the concrete. Hou and Wang's numerical modeling (12) found that aggregate shape has little effect on the compression resistance of concrete. Although the above literature focuses on concrete, it is applicable only to standard gradation; the gradation characteristics of CSG with unscreened aggregates remain to be studied further.

Separately, fractal theory was introduced into the study of material structure, opening a new avenue for quantifying the relationship between material complexity and macroscopic properties. Yu (13) described the statistical properties of porous media based on fractal theory and fractal technology. Zhang and Jin (14) studied the application of fractal theory to concrete pore structures. Gao et al. (15) and Hu et al. (16) described and quantified the fractal characteristics of aggregate appearance and outlines using the method of fractal dimensions. $\mathrm{Li}$ et al. (17) adopted fractal dimensions to describe the particle shape and gradation of concrete aggregates.

Based on different gradation characteristics of natural sand gravels at the project site, this study uses numerical simulation to obtain the maximum density gradation attainable by adding artificial aggregates. Fractal theory is applied to characterize aggregate properties and to further explore the effects of aggregate fractal characteristics on CSG macroscopic and mesoscopic mechanical behavior. This provides a theoretical basis for mix proportion design in other engineering applications.

\section{MATERIALS AND METHODS}

\subsection{Fractal Theory}

Fractal geometry (18) was founded by the French-American mathematician, Benoit Mandelbrot. As an emerging science describing the irregularity and complexity of materials, it offers a new way to study the quantitative relationship between aggregate complexity and the mechanical properties of CSG.

\subsubsection{Fractal Model Based on Aggregate Gradation}

Aggregate gradation refers to the proportional relationship between the numbers of aggregate particles of different sizes. Traditional aggregates are divided into small stones $(5-20 \mathrm{~mm})$, medium stones $(20-40 \mathrm{~mm})$, large stones $(40-80 \mathrm{~mm})$ and 
super-large stones $(80-150 \mathrm{~mm})$ according to particle size. Such an irrational gradation indicates poor aggregate density, and reduces the performance of the composite material.

Based on the gradation method, a fractal model was established for aggregate gradation of CSG (19). The resulting fractal function for graded CSG aggregates is (Equation [1]):

$$
P_{r}=\left(\frac{r^{3-D_{g}}-r_{\min }^{3-D_{g}}}{r_{\max }^{3-D_{g}}-r_{\min }^{3-D_{g}}}\right) P_{0}
$$

where $r$ represents the size of a sieve pore for grading particles; $r_{\min }$ and $r_{\max }$ represent the smallest and largest particle sizes, respectively; $\mathrm{D}_{\mathrm{g}}$ represents the fractal dimension of the aggregate size mass distribution; and $\mathrm{P}_{0}$ represents the pass rate at the maximum nominal particle size. Because $r_{\min }$ is much smaller than $r_{\max }$, Equation [1] can be simplified to Equation [2]:

$$
P_{r}=\left(\frac{r}{r_{\max }}\right)^{3-D_{g}} P_{0}
$$

In accordance with the above formula, the fractal dimension $\mathrm{D}_{\mathrm{g}}$ of the aggregate gradation can be obtained.

\subsubsection{Fractal Model Based on Aggregate Shape}

The section of an aggregate is rough and complex with obvious fractal characteristics; this can be represented by the box dimension. One of the most widely used fractal dimensions, its mathematical expression is as follows: supposing that is any non-empty bounded subset on $\mathrm{R}$ and $\mathrm{N}_{\delta}$ is the minimum number of boxes of size $\delta$ that can cover the set $\mathrm{F}$, the box dimension can be obtained through the following Equation [3] (14):

$$
\mathrm{D}_{\mathrm{x}}=\lim _{\delta \rightarrow 0} \frac{\ln \mathrm{N}_{\delta}(\mathrm{F})}{\ln (1 / \delta)}
$$

where $\delta$ represents the unit measurement scale in a continuous distribution, i.e., a unit square used in the two-dimensional plane; $N_{\delta}$ represents the number of measurement scales, which is the number of small squares covering polygonal aggregates; and $D_{x}$ represents the box dimension of an aggregate shape.

\subsection{Random CSG Aggregate Model}

\subsubsection{Generation of Random Aggregates}

In the generation of random aggregates, a group of random variables uniformly distributed on the interval $[0,1]$ were first generated by the Monte Carlo method (20-22). The probability density function with $\mathrm{X}$ was assumed to be as follows Equation [4]:

$$
f(x)=\left\{\begin{array}{l}
1, x \in[0,1] \\
0, x \notin[0,1]
\end{array}\right.
$$

Random variables on any other intervals can be obtained from the transformation of random variables on the interval $[0,1]$. For example, the uniformly distributed random variable $\mathrm{Y}$ on any interval $[\mathrm{a}, \mathrm{b}]$ can be obtained by $\mathrm{Y}=\mathrm{a}+(\mathrm{b}-\mathrm{a}) \mathrm{X}$. Thus, random variables that meet the uniform distribution on each interval were generated.

The position of aggregates within different particle size ranges in the test pieces was randomly determined using the Monte Carlo method. The number of aggregate particles was obtained from the gradation of concrete and the occupancy of aggregates was determined using the Fuller gradation theory based on the principle of maximum density.

According to the Walaraven Equation (23), a three-dimensional aggregate gradation curve can be transformed into a two-dimensional planar aggregate gradation curve. The cumulative distribution probability of aggregates with diameter D less than $\mathrm{D}_{0}$ was calculated as follows Equation [5]:

$$
\begin{aligned}
& P_{c}\left(D<D_{0}\right)=P_{K}\left[1.065\left(D_{0} / D_{\max }\right)^{\frac{1}{2}}-0.053\left(D_{0} / D_{\max }\right)^{4}-\right. \\
& \left.0.012\left(D_{0} / D_{\max }\right)^{6}-0.0045\left(D_{0} / D_{\max }\right)^{8}+0.0025\left(D_{0} / D_{\max }\right)^{10}\right]
\end{aligned}
$$

where $P_{k}$ represents the occupancy fraction of aggregates, for which a value of $70 \%$ was used in this study. In accordance with Equation [5], the number of aggregate particles at various levels of the cross section can be calculated.

\subsubsection{Inversion of Mesoscopic Material Parameters}

CSG test cubes of $100 \mathrm{~mm} \times 100 \mathrm{~mm} \times 100 \mathrm{~mm}$ were used in the experiment. Based on laboratory conditions, standard grade II aggregates were adopted with the mix proportions shown in Table 1.

TABLE 1. Mix proportions used in the uniaxial compression test.

\begin{tabular}{cccccc}
\hline Cement $\left(\mathrm{kg} / \mathrm{m}^{3}\right)$ & Flash $\left(\mathrm{kg} / \mathrm{m}^{3}\right)$ & Sand $\left(\mathrm{kg} / \mathrm{m}^{3}\right)$ & Water $\left(\mathrm{kg} / \mathrm{m}^{3}\right)$ & Aggregate $\left(\mathrm{kg} / \mathrm{m}^{3}\right)$ & Sand rate \\
\hline 70 & 20 & 434 & 90 & 1736 & 0.2 \\
\hline
\end{tabular}


The test pieces were cured for $28 \mathrm{~d}$ for the uniaxial compression test. In the test, a universal testing machine and a displacement control method were used to obtain the stress-strain curve.

From a mesoscopic perspective, CSG can be seen as a three-phase composite material composed of sand gravel aggregates, a mortar matrix, and interfaces between the mortar matrix and the aggregates. In the two-dimensional plane, it was assumed that the natural sand gravel aggregates are round and the artificial sand gravel aggregates polygonal. In this study, by generating aggregate random circles and adhesive random circles with boundaries, the inner and outer circles were divided into quadrants. The number of corner points for each quadrant was determined, and the corner point coordinates were formed. Finally, the corner points were connected to generate polygons (24).

The constitutive relationship and failure criterion for mesoscopic component materials were selected simply. The constitutive model of each component adopted a linear elastic model while the failure criterion adopted the maximum stress criterion; that is, when the tensile stress in a material exceeds its maximum tensile strength, the material is assumed to crack.

In the finite element calculations, the material parameters of each component included the tensile strength, elastic modulus, and Poisson's ratio. Since the parameters of meso-component materials were difficult to measure, minimizing the difference between stress-strain curves obtained from experiments and numerical simulation was taken as the optimization goal to obtain the parameters by means of inversion (25-27). The comparison between numerical simulation results and lab uniaxial compression tests is shown in Figure 1.

Figure 1 shows that the peak stress in the experiment is slightly lower than that in the numerical simulation and the strain values are basically the same. Moreover, the correlation coefficient between the two curves is very high. After failure, the measured curve shows a descent stage while the simulation results show brittle failure with less of a decline. This is caused by the unreasonable description of the yield failure criterion used; however, the numerical simulation described the main mechanical properties quite well. The values of the mesoscopic parameters obtained from inversion are shown in Table 2.

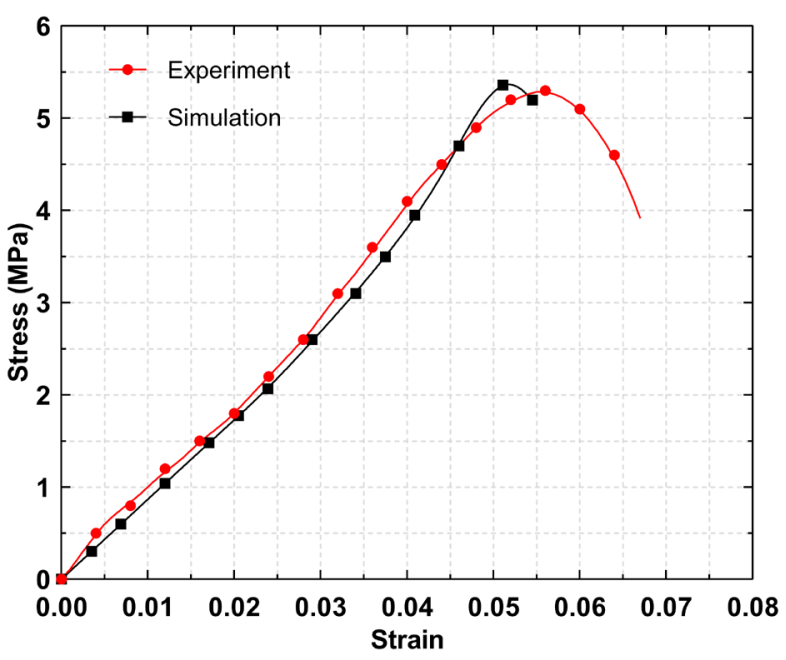

Figure 1. Parameter inversion results.

Aggregate shape has a remarkable impact on the interface $(28,29)$, but because the interface occupied a very small proportion of the CSG, the impact of aggregate characteristics on mesoscopic parameters was ignored in this study.

\section{RESULTS}

CSG aggregates usually come from the project site and have round or near-round shapes. In principle, they are used without screening, giving rise to a complex gradation. The research of Feng (1) showed that natural sand gravels at project sites have alternately distributed sand and gravel layers with uneven gradation (see Figure 2), causing a significant strength decrease in the resulting CSG. Figure 2 shows the gradation and Fuller curves of the 12 groups of on-site aggregates. The gradation of onsite aggregates deviates markedly from the standard Fuller gradation. Therefore, the gradation must be adjusted using artificial aggregates (30).

For projects lacking natural riverbed sand gravels, artificial aggregates can be used to replace natural aggregates. Artificial aggregates are generally shaped as irregular polygons. Their surfaces are relatively rough and irregular with more edges and corners than natural aggregates. Artificial gravel aggregates supplement natural gravel aggregates

TABLE 2. Mesoscopic component parameters.

\begin{tabular}{lccc}
\hline Meso component & Elastic modulus $(\mathrm{MPa})$ & Poisson's ratio & Tensile strength (MPa) \\
\hline Aggregate & 210 & 0.16 & 0.5 \\
\hline Cement mortar & 65 & 0.20 & 0.5 \\
\hline Interface & 32 & 0.16 & 0.4 \\
\hline
\end{tabular}




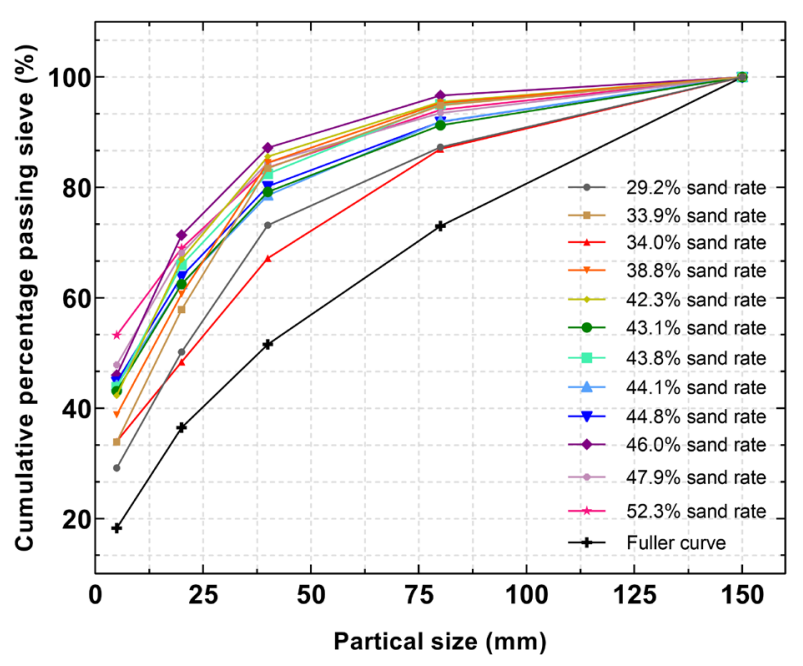

FiguRE 2. Gradation and Fuller curves of the 12 groups of aggregates (based on data in (1)).

at dam sites, allowing the aggregate gradation of CSG to be adjusted. In order to mix aggregates in a logical way, the aggregates' characteristics must be quantified. Owing to the complex gradations and shapes of aggregates, fractal theory was introduced in this work to quantify their characteristics.

\subsection{Fractal Characteristics Based on Aggregate Gradation}

The impact of aggregate gradation characteristics on CSG was compared with Fuller gradation, which was taken as the standard gradation (BZ) of aggregates and was combined with cemented sand and gravel site aggregates. The on-site gradations with sand rates of $29.2 \%$ and $38.8 \%$ were selected as control gradation 1 (DZ1) and control gradation 2 (DZ2), respectively. The cumulative percentage of particles passing the sieve is illustrated in Figure 2 and the cumulative screening rate is shown in Table 3.

TABLE 3. Cumulative distribution of grade II aggregates.

\begin{tabular}{ccccccccc}
\hline \multirow{2}{*}{ No. } & \multicolumn{8}{c}{ Sieving particle size $(\mathrm{mm})$} \\
\cline { 2 - 9 } & 40 & 35 & 30 & 25 & 20 & 15 & 10 & 5 \\
\hline BZ & 100.0 & 94.0 & 87.0 & 79.0 & 71.0 & 61.0 & 50.0 & 35.0 \\
\hline DZ1 & 100.0 & 93.0 & 85.5 & 77.4 & 68.6 & 61.3 & 52.3 & 39.9 \\
\hline DZ2 & 100.0 & 93.8 & 87.2 & 79.9 & 71.8 & 65.4 & 57.4 & 45.9 \\
\hline
\end{tabular}

Since the Fuller curve model was highly consistent with the power function curve, the cumulative aggregate distribution curve was transformed into the same form as Equation (2) to determine its frac- tal dimension. The aggregate standard gradation curve (BZ) is expressed as Equation [6]:

$$
P_{r}=15.568 \times r_{i}^{0.5049}
$$

According to the above formula and Equation [2], the fractal dimension of the standard gradation was 2.4951 .

The fractal dimensions of the three gradations obtained are shown in Table 4 . Figure 3 presents the fractal curves of the grading qualities obtained for the three aggregate grading curves listed in Table 3.

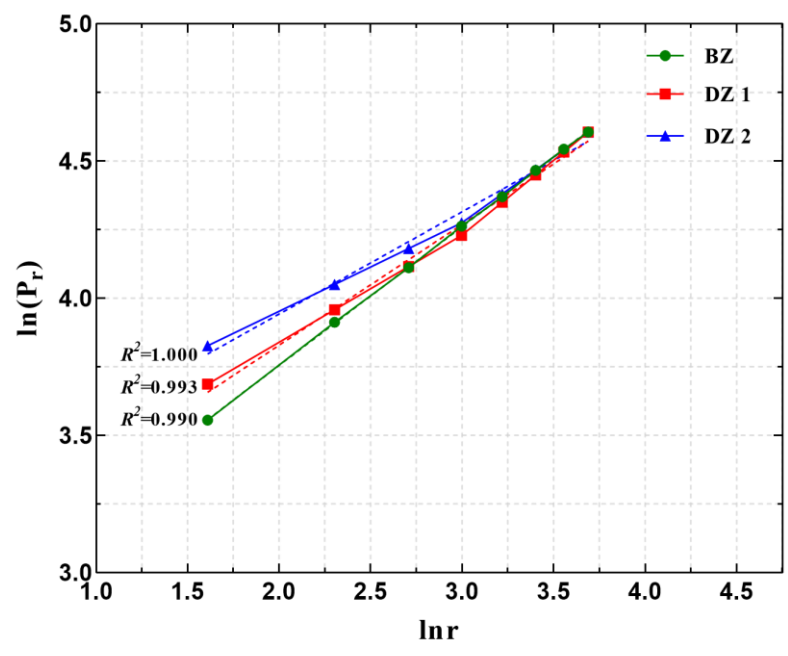

Figure 3. Mass fractal curves of gradations BZ, DZ1, and DZ2.

TABLE 4. Calculated fractal dimensions for the gradations BZ, $\mathrm{DZ} 1$, and DZ2.

\begin{tabular}{cccc}
\hline No. & Slope K & Fractal dimension $D_{g}$ & $R^{2}$ \\
\hline BZ & 0.5049 & 2.4951 & 1.000 \\
\hline DZ1 & 0.4404 & 2.5596 & 0.993 \\
\hline DZ2 & 0.3730 & 2.6270 & 0.990 \\
\hline
\end{tabular}

Table 4 and Figure 3 show that, as the cumulative aggregate screening rate approaches the standard value, the curve steepens and the fractal dimension decreases. That is, for aggregates with significant fractal characteristics within the same scale range, the larger the fractal dimension, the poorer the gradation; conversely, the smaller the fractal dimension, the better the gradation.

\subsection{Fractal Characteristics Based on Aggregate Shape}

Natural sand gravel aggregates are generally round and artificial aggregates are generally polyg- 
onal. In order to study the effect of the mix proportion of different shapes of sand gravel aggregates on the performance of CSG, the fractal characteristics of mixed aggregates were determined as listed in Table 5.

TABLE 5. Fractal characteristics of mixed aggregates.

\begin{tabular}{ccc}
\hline No. & \multicolumn{2}{c}{ Aggregate proportion (\%) } \\
\hline & Round & Polygonal \\
\hline LC1 & 0 & 100 \\
\hline LC2 & 20 & 80 \\
\hline LC3 & 40 & 60 \\
\hline LC4 & 60 & 40 \\
\hline LC5 & 80 & 100 \\
\hline LC6 & 100 & 0 \\
\hline
\end{tabular}

Based on Equation [3], the mixing ratios (LC1, LC2, LC3, LC4, LC5) of the above-mentioned five different shapes of aggregates are calculated, and the fractal dimension regression calculation results are shown in Figure 4 and Table 6. Since there were no polygonal aggregates in LC6, it was not required to calculate its fractal dimension.

Table 6 summarizes the fractal dimension regression results and Figure 4 shows the fractal curves for different aggregate shapes.

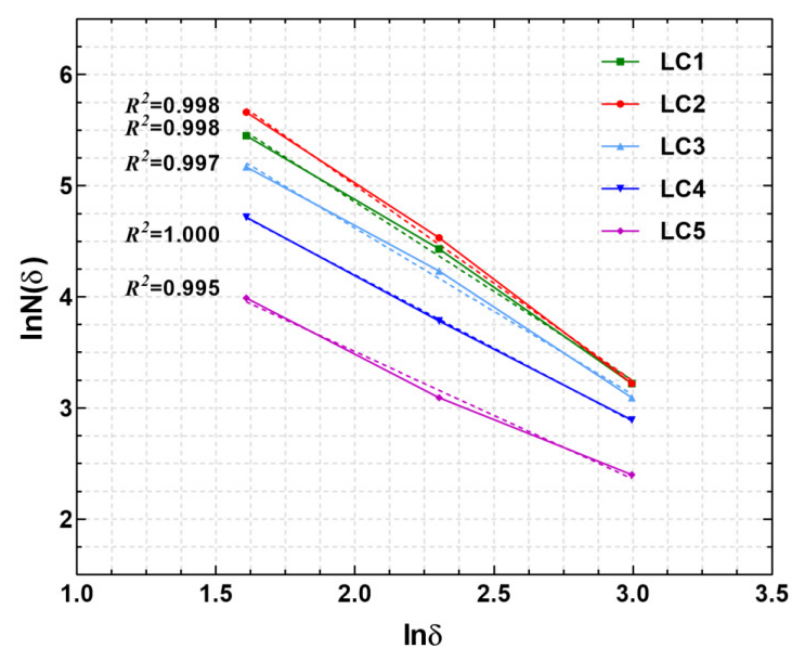

FIGURE 4. Fractal curves for different aggregate shapes.

According to Table 6 and Figure 4, as the proportion of polygonal (artificial) aggregates in CSG decreases, aggregate shape complexity and fractal dimension decrease. That is, within the same scale range, the larger the fractal dimension, the more polygonal the artificial aggregates; conversely, the smaller the fractal dimension, the less the polygonal the artificial aggregates.

TABLE 6. Calculation results of fractal dimension based on aggregate shape.

\begin{tabular}{ccc}
\hline No. & Fractal dimension $D_{x}$ & $\mathrm{R}^{2}$ \\
\hline LC1 & 1.7630 & 0.998 \\
\hline LC2 & 1.6102 & 0.998 \\
\hline LC3 & 1.5000 & 0.997 \\
\hline LC4 & 1.3187 & 1.000 \\
\hline LC5 & 1.1477 & 0.995 \\
\hline
\end{tabular}

\section{DISCUSSION}

Based on the results obtained, the following discussion examines the effects of aggregate characteristics on CSG mechanical behavior. In particular, the relationships between aggregate gradation and shape fractal dimensions and resulting CSG mechanical behavior are discussed.

\subsection{Effect of Aggregate Gradation Fractal Dimension}

The effect of aggregate gradation on the mechanical behavior of CSG was studied based on the three aggregate gradations described in 3.1: the standard gradation (BZ), control gradation 1 (DZ1), and control gradation 2 (DZ2). The random aggregate models in which all aggregates were artificial (LC1) are shown in Figure 5 for the three gradations, and the corresponding stress-strain curves obtained from numerical simulations are shown in Figure 6.

As the aggregate gradation approaches the standard gradation, the fractal dimension of the aggregate gradation decreases and the peak stress increases. Simultaneously, as the aggregate gradation improves, the tangent slope of the stress-strain curve increases; that is, the elastic modulus increases. This occurs because, as the aggregate gradation approaches the standard gradation, the aggregate quantity increases, improving the aggregate density; thus, both the strength and elastic modulus increase. This is consistent with experimental results in the literature (31) and validates the research method used in this study.

\subsection{Effect of Aggregate Shape Fractal Dimension}

The effect of aggregate shape on the mechanical behavior of CSG was analyzed in accordance with the relationship between fractal characteristics 


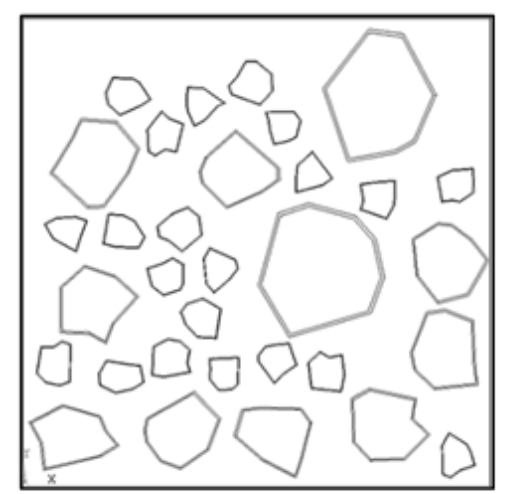

(a) $\mathrm{BZ}$

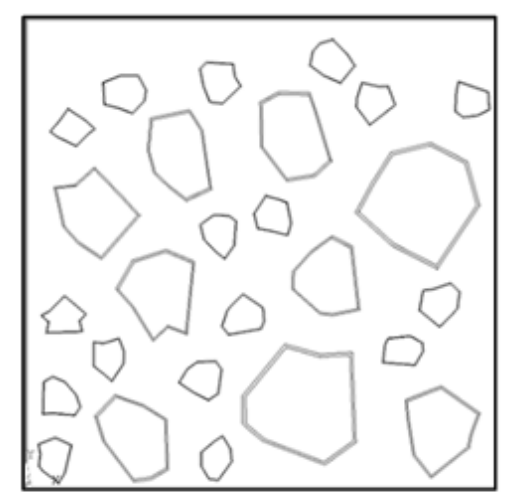

(b) DZ1

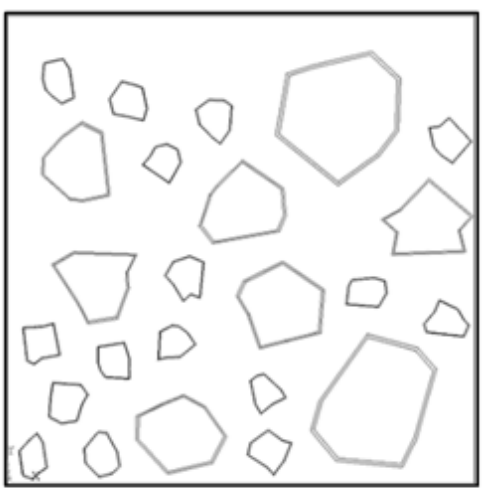

(c) DZ2

FIGURE 5. Random aggregate models considering different gradations with the same aggregate shapes.

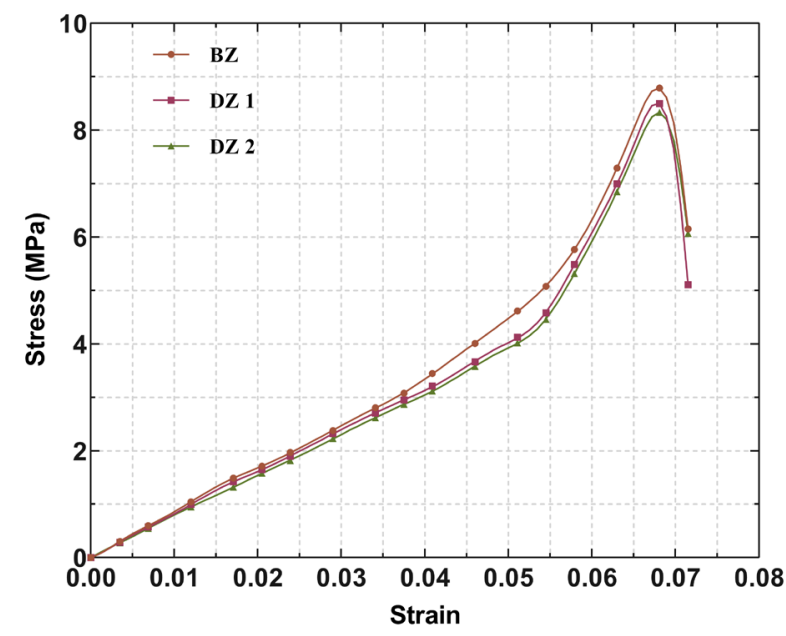

FIGURE 6. Stress-strain curves for different aggregate gradations.

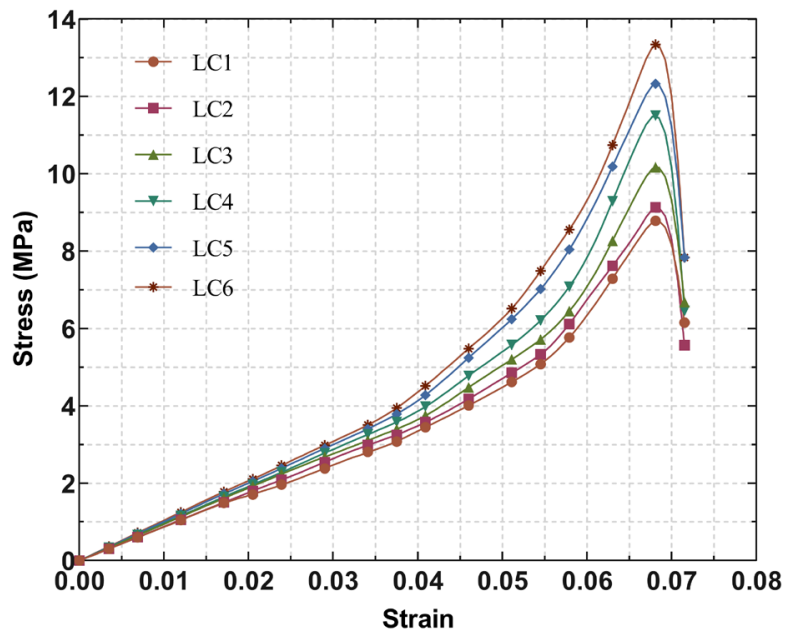

FiguRE 8. Stress-strain curves for different aggregate shapes.

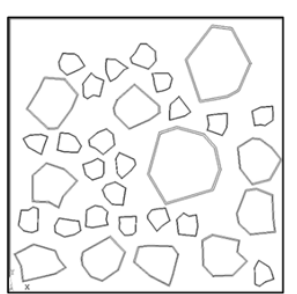

(a) LC1

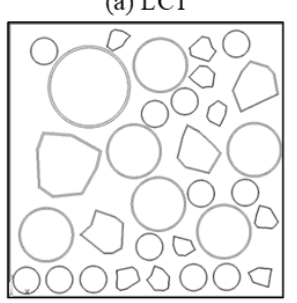

FIGURE 7. Random aggregate models considering different aggregate shapes with the same gradation.

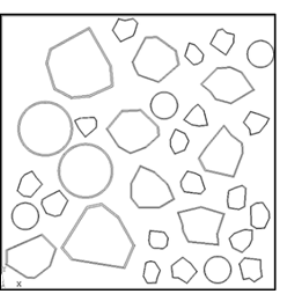

(b) LC2
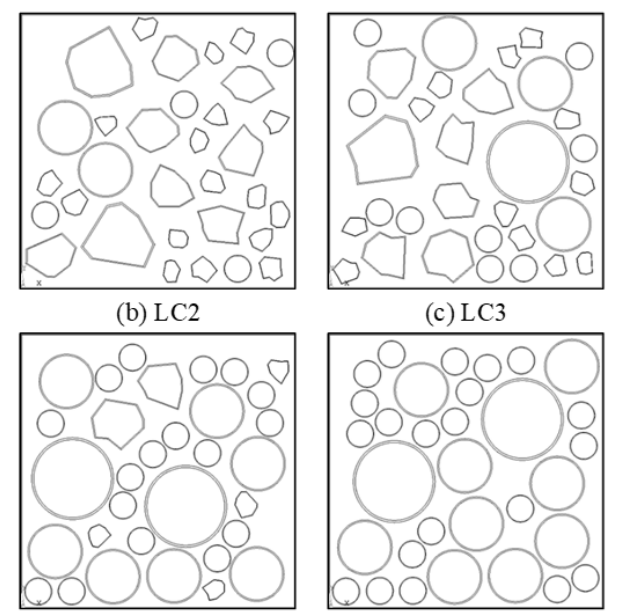

(c) LC3

(1)

and mechanical characteristic parameters. Figure 7 shows the models of different aggregate shapes under the standard gradation.

Figure 8 shows the stress-strain curves under uniaxial compression obtained for the models illustrated in Figure 7.

Figure 7 and Figure 8 show that, as the proportion of polygonal aggregates increases (i.e., as the aggregate shape fractal dimension increases), the peak stress and the tangent slope of the stress-strain curve both decrease: that is, the elastic modulus decreases. This is consistent with experimental results in literature (32-35). There are several possible explanations for this phenomenon: the influence of corner edges and of stress concentration.

Considering the impact of the corner edges, the area of the interfacial transition zone (ITZ) units around the polygonal aggregates is larger than that around the circular aggregates of the same volume. Under the 


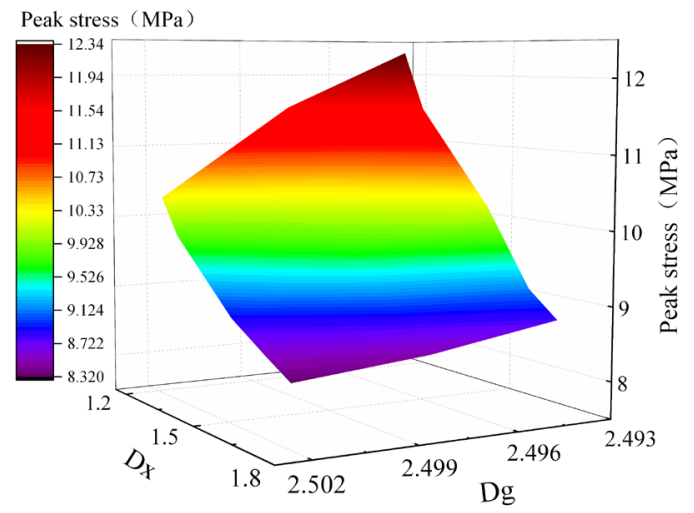

Figure 9. Peak stress corresponding to the shape (Dx) and gradation $(\mathrm{Dg})$ fractal dimensions of different aggregates.

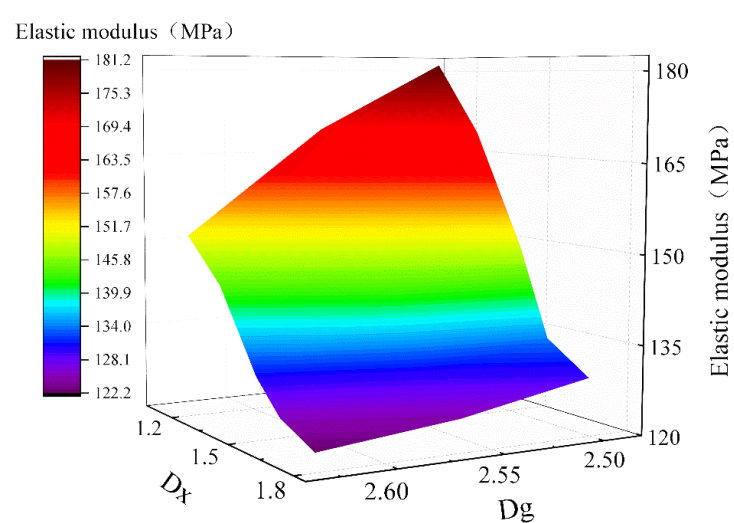

FIgURE 10. Elastic modulus corresponding to the shape (Dx) and gradation $(\mathrm{Dg})$ fractal dimensions of different aggregates.

best performance. When 20\% artificial aggregate content was added under the standard gradation considered in this study, the elastic modulus and peak stress reached their maximum values; this scenario was suitable for on-site mixing. The method used in this study to investigate the impact of complex aggregates on CSG mechanical properties through fractal theory and numerical simulation can provide a theoretical reference for other CSG projects.

\section{CONCLUSIONS}

In view of the complex characteristics of CSG aggregates, the concept of fractal dimensions was introduced to quantify aggregate gradation and shape. A two-dimensional random aggregate model of CSG was established, and mechanical properties of CSG under different aggregate gradation and shape fractal dimensions were studied through parameter inversion. The following conclusions were drawn:

1. The closer the aggregate gradation to the standard gradation, the smaller the fractal dimension of the aggregate gradation; as the proportion of polygonal aggregates increased, the aggregate shape fractal dimension increased.

2. According to uniaxial compression numerical testing, as the aggregate gradation fractal dimension decreased, both the peak stress and elastic modulus of CSG increased.

3. According to uniaxial compression numerical testing, as the aggregate shape fractal dimension increased, both the peak stress and elastic modulus of CSG decreased.

4. For mixing artificial aggregates with natural aggregates from riverbeds, a mix proportion for optimal mechanical properties was obtained; this could provide a theoretical basis for similar projects. 
5. Due to the limited test methods available for this study, the mesoscopic numerical simulation technique in this work did not consider the effect of aggregate shape on interface performance; this topic requires further research in the future.

\section{ACKNOWLEDGMENTS}

This research was funded by National Key research and Development Project of China: (2018YFC0406803) physical and numerical model and evolution law of performance of cemented granular material dam, open project of Research Centre on Levee Safety \& Disaster Prevention Ministry of Water Resources: (2018008) research on characteristics and optimization of cemented gravel flood control dike, Graduate Education Innovation Program Fund of North China University of Water Resources and Electric Power: (YK2020-06) Meso-damage mechanism and evolution rule of cement sand and gravel under freeze-thaw action and Henan Provincial Natural Science Foundation Project: (202300410270) Research on Frost Resistance Durability Behavior and Deterioration Damage Mechanism of Cemented Sand and Gravel.

\section{REFERENCES}

1. Feng, W. (2013) Research on characteristics of damming materials for cemented gravel dam and engineering application, China Institute of Water Resources and Hydropower Research, Beijing, China.

2. González-Fonteboa, B.; Seara-Paz, S.; de Brito, J.; González-Taboada, I.; Martínez-Abella, F.; Vasco-Silva, R. (2018) Recycled concrete with coarse recycled aggregate. An overview and analysis. Mater. Construcc. 68 [330], e151. https:// doi.org/10.3989/mc.2018.13317.

3. Shafigh, P.; Asadi, I.; Akhiani, A.R.; Mahyuddin, N.B.; Hashemi, M. (2020) Thermal properties of cement mortar with different mix proportions. Mater. Construcc. 70 [339], e224. https://doi.org/10.3989/mc.2020.09219.

4. Jin, L.; Yu, W.; Du, X.; Yang, W. (2020) Meso-scale simulations of size effect on concrete dyna-mic splitting tensile strength: Influence of aggregate content and maximum aggregate size. Eng. Fract. Mech. 230, 106979. https://doi.org/10.1016/j.engfracmech.2020.106979.

5. Huang, X.F. (2010) Effect of coarse aggregate shape on concrete physical and mechanical properties, Zhejiang University of Technology, Zhengjiang, China (2010).

6. Guo, D. (2016) Research on the main technical requirements of high-quality concrete aggregates, Beijing University of Architecture, Beijing, China (2016).

7. Sánchez-Roldán, Z.; Valverde-Palacios, I.; Valverde-Espinosa, I.; Martín-Morales, M. (2020) Microstructural analysis of concretes manufactured with recycled coarse aggregates presoaked using different methods. Mater. Construcc. 70 [339], e228. https://doi.org/10.3989/mc.2020.16919.

8. Zhang, Y.; Yan, L.; Wang, S.; Xu, M. (2019) Impact of twisting high-performance polyethylene fibre bundle reinforcements on the mechanical characteristics of high-strength concrete. Mater. Construcc. 69 [334], e184. https://doi. org/10.3989/mc.2019.01418.

9. Xiong, X.Y.; Xiao, Q.S. (2019) A unified meso-scale simulation method for concrete under both tension and compression based on Cohesive Zone Model. J. Hydraul. Eng. 50, 448462. https://doi.org/10.13243/j.cnki.slxb.20181061.
10. Wang, X.F.; Yang, Z.J.; Yates, J.R.; Jivkov, A.P., Zhang, Ch.. (2015) Monte Carlo simulations of mesoscale fracture modelling of concrete with random aggregates and pores. Constr. Build. Mater. 75, 35-45. https://doi.org/10.1016/j. conbuildmat.2014.09.069.

11. Zheng, J.C.; Zhu, L.; Peng, G. (2013) Numerical simulation of concrete axial tensile performance based on mesomechanics. Engineering Journal of Wuhan University. 46, 188-193.

12. Hou, Y.X.; Wang, L.C. (2009) Generating method of random polygon aggregate in mesoscopic simulation of concrete. J. Archit. Civil. Eng. 26, 59-65.

13. Yu, B.; Li, J. (2001) Some fractal characters of porous media. Fractals. 9 [3], 365-372. https://doi.org/10.1142/ S0218348X01000804.

14. Zhang, J.X.; Jin, S.S. (2013) Micropore structure of cement concrete and its function, Science Press, Beijing, China.

15. Gao, S.; Guo, Y.X.; Wu, B.Q. (2019) Research on Fractal characteristics of the recycled fi-ne aggregate. Concrete. 6,78 83. https://doi.org/10.3969/j.issn.1002-3550.2019.06.018.

16. Hu, H-x.; Zhang, Q.; Ding, D-h. (2010) Study on the mechanical properties of the concrete materials based on fractal theory. Concrete. 6, 31-33,36. https://doi.org/10.3969/j. issn.1002-3550.2010.06.009.

17. Li, W.T.; Sun, H-q.; Xing, J. (2003) Theory of fractal applied to concrete study. Journal of Hebei University of Technology. 32, 13-16.

18. Mandelbrot, B.B. (1982) The fractal geometry of nature. W. H. Freeman, New York.

19. Chang, Y.J. (2018) Fractal characteristics and the application for asphalt mixture grading with the curve models. Journal of Heilongjiang Institute of Technology. 32, 6-10. https://doi.org/10.19352/j.cnki.issn16714679.2018.06.002.

20. Bai, W.; Peng, G. (2007) Monte-Carlo method aggregate random structures for concretes by Ansys, Journal of Shihezi University (Natural Science). 25, 504-507. https://doi. org/10.13880/j.cnki.65-1174/n.2007.04.014.

21. Rong, M.D.; Guo, Z.Y.; Wu, X.Q. (2017) Ansys implementation of two-dimensional and three-dimensional random aggregate model generated by Monte Carlo method. Construction Machinery Technology and Management. 30, 7173. https://doi.org/10.13824/j.cnki.cmtm.2017.11.019.

22. Li, Z.W. (2007) Monte Carlo simulation of related random variables. Stat. Decis. 5, 9-10.

23. Schlangen, E.; van Mier, J.G.M. (1992) Simple lattice model for numerical simulation of fracture of concrete materials and structures. Mater. Struct. 25, 534-542. https://doi. org/10.1007/BF02472449.

24. Guo, L.X.; Zhong, L.; Zheng, C.Y. (2019) Damage and destruction research of recycled concrete with waste brick based on modified random aggregate model. J. Basic Eng. 27, 1390-1398. https://doi.org/10.16058/j.issn.10050930.2019.06.018.

25. Xiao, J.Z.; Du, J.T. (2008) Complete stress-strain curve of concrete with different recycle coarse aggregates under uniaxial compression. J. Build. Mater. 11, 1445-1449. https://doi.org/10.3969/j.issn.1007-9629.2008.01.021.

26. Peng, Y.J.; Wang, Y.H. (2006) Numerical analyses for fracture process and failure mechanism of concrete on meso-level. Chin. Saf. Sci. J. 16, 110-114. https://doi.org/10.16265/j.cnki.issn1003-3033.2006.08.020.

27. Shang, X.Y.; Yang, J.W.; Li, J.S. (2020) Fractal characteristics of meso-failure cracks in re-cycled coarse aggregate concrete based on CT image. Acta. Mater. Compos. Sin. https://doi.org/10.13801/j.cnki.fhclxb.20190917.002.

28. Prokopski, G.; Halbiniak, J. (2000) Interfacial transition zone in cementitious materials. Cem. Concr. Res. 30 [4], 579-583. https://doi.org/10.1016/S0008$8846(00) 00210-6$.

29. Xu, Y.S. (2017) Research on mesoscopic model of concrete considering aggregate shape, Southeast University, Nanjing.

30. Guo, L.; Zhang, Y.; Zhong, L.; Wang, M.; Zhu, X. (2020) Study on macroscopic and mesoscopic mechanical behavior of CSG based on inversion of mesoscopic material parameters. Sci. Eng. Compos. Mater. 27, 65-72. https://doi. org/10.1515/secm-2020-0007. 
31. Ashraf, W.B.; Noor, M.A. (2011) Performance-evaluation of concrete properties for different combined aggregate gradation approaches. Proce. Eng. 14, 2627-2634. https://doi.org/10.1016/j.proeng.2011.07.330.

32. Du, C-B.; Sun, L-G. (2007) Numerical simulation of aggregate shapes of two-dimensional concrete and its application. J. Aerospace Eng. 20 [3], 172-178. https://doi.org/10.1061/ (ASCE)0893-1321(2007)20:3(172).

33. Du, C-B.; Sun, L-G.; Jiang, S.Y. (2013) Numerical simulation of aggregate shapes of three-dimensional concrete and its application. J. Aerospace Eng. 26 [3], 515-527. https://doi. org/10.1061/(ASCE)AS.1943-5525.0000181.

34. Cui, W.; Yan, W-s.; Song, H-f.; Wu, W-1. (2020) DEM simulation of SCC flow in L-Box set-up: Influence of coarse aggregate shape on SCC flowability. Cem. Concr. Сотр. 109, 103558. https://doi.org/10.1016/j.cemconcomp.2020.103558

35. Tian, M.Y. (2019) Numerical calculation of concrete uniaxial mechanical properties based on mesoscale, Taiyuan University of Technology, Taiyuan, China.

36. Chen, P.; Chen, X.; Wang, Y.; Wang, P. (2020) Preliminary study on the upcycle of non-structural construction and demolition waste for waste cleaning. Mater. Construcc. 70 [338], e220. https://doi.org/10.3989/mc.2020.13819.

37. Chen, H.Q.; Ma, H.F.; Li, Y.C. (2007) Influence of random aggregate shapes on flexural strength of dam concrete. J. Chin. Inst. Water. Resour. Hydr. Res. 04, $241-$ 246. https://doi.org/10.13244/j.cnki.jiwhr.2007.04.003. 